Professor Heilprin compares the irregularities of this bad material. denounced by me as bad, and concludes that it is good evidence for doubting the value of that which was considered to be more reliable. Such reasoning obviously affords only a non sequitur. I do not think any one who has passed laborious days and nights in the determination of angles by repetition and reversal will agree with Professor Heilprin that the system of " extracting averages" is "delusive;" and a reference to my report will show that it was a question of comparison of a verages with a view to the weighing of methods with which, in that instance, I was concerned, which could hardly delude any one who chose to read what was printed on the pages before him. Averages may be made delusive, but not when used in this manner.

In conclusion, although the whole subject is one for experts and professional surveyors rather than others, I may summarize for those who are interested and unprofessional the main features of what was done in 1874 for the purpose of getting at the height of that unattainable peak.

In the determination of any height by triangulation, there are to be considered the character of the instruments, the distance of the peak, the vertical angle measured, and the refraction of the atmosphere, which distorts the line of sight and introduces an error, tolerably constant for high angles and short distances in ordinary latitudes, but irregular and sometimes very great in angles measured when the line of sight passes near the surface of the earth, especially for long distances and in high latitudes.

In the case of Mount St. Elias the distance depended upon a horizontal triangle observed from two astronomically determined stations, giving an astronomical base-line from which the lines converging on the peak were obtained by an astronomical azimuth. The value of such an intersection depends somew hat upon the size of the angle, which in this case was large, nearly $60^{\circ}$. The liability to error which very small angles of intersection may introduce was therefore measurably avoided.

The positions of the ends of the base-line were well determined. The circumstances of the observation made at sea were eminently favorable. The error of this position could hardly have exceeded three miles on the worst assumption; and the error of distance which this would produce in the base of the vertical triangle, upon which the hejght depended, was trifling. The instruments were first-class of their kind. The vertical angle measured, I venture to say, is beyond dispute. The uncertainty remaining, therefore, was in regard to the refraction,-a factor beyond our power to determine, and equally undetermined in all observations made to date.

However, the height of Mount Fairweather was tolerably well determined from positions near its case. We reasoned the error of refraction might be assumed to be the same for both mountains at the same moment, both being visible and not differing very greatly in their distance from our station. The difference between the height of Fairweather as measured from near its base, and that which we might obtain for it from our Port Mulgrare station, might be assumed to be due to refraction, and an analogous amount applied to the result for St. Elias as a correction for that unknown error. This was an assumption, of course, but a reasonable one, and was adopted.

The height of Mount St. Elias may very possibly be less than our results would show; but that they were likely to be correct within certain limits seemed probable, from the fact that angles measured by Malespina in the last century, the record of which is fortunately preserved, when computed with a corrected base-line in accordance with our observations for the position of the mountain, gave results approximating our own, - -an apparent confirmation which was certainly impressive.

The outline of our proceedings is given, as above, in entirely untechnical language, but those who are professionally qualified to judge the character of such work are confidently invited to examine the report itself in the Coast Surrey volume for 1875 . This is somewhat amplified from the extra advance copies which were distributed before the publication of the volume. I make no pretence to the character of a geodetic expert, but the comparatively simple computations contained in this report were prepared and reviewed by those who are; and the error, if error there be in the results, is due to factors which were entirely independent of the observers or the computers, under the circumstances.

Smithsonian Institution, Washington, D.C., Nov. 11. WM. H. DALL.

\section{Chalk from the Niobrara Cretaceous of Kansas.}

Referring to Professor S. W. Williston's interesting communication in Science for Oct. 31, on microscopic organisms from the chalk of the Niobrara cretaceous of Kansas, I should suppose it to be highly probable that the forms met with by him are, as he supposes, coccoliths. Coccoliths are rery abundant in, and sometimes form a notable proportion of, the calcareous parts of the Niobrara beds in Manitoba and in Nebraska, and are there associated with foraminifera and with rhabdoliths, to which latter class the slender, rod-like bodies, also noted by Professor Williston, may be referrible. Figures and a description of a number of varieties of coccoliths and rhabdoliths from the cretaceous of Manitoba may be found in the Canadian Naturalist for April, 1874 (p. 256).

Geological Survey of Canada, Nov. 10. George M, Dawson.

\section{BOOK-REVIEWS}

Races and Peoples. By Daniel G. Brinton. New York, N. D. C. Hodges. $8^{\circ} . \$ 1.75$.

Dr. BRINTon has undertaken the difficult task of presenting the whole vast field of anthropological science in a concise and readable form, and he has admirably succeeded in giving us a book that is attractive, and, in all its parts, suggestive. Therefore not only will it prove useful in making the public acquainted with the facts and some theories of ethnological science, but it will also incite the painstaking student to more thorough investigation of mooied questions, and open new vistas in many fields of research. Dr. Brinton's theories, even such as may not appear acceptable, are always full of ingenuity, and certainly worth the careful attention of anthropologists. The present book, notwithstanding the brief ness with which necessarily all problems are treated, teems with new ideas and excellent critical remarks. In reviewing it, we must confine ourselves to selecting a fer of the more important points. On the whole, we might wish that some still very doubtful theories to which the author adheres were not presented with quite as much assurance as finally settled.

The introductory chapter, on "The Physical Elements of Ethnography," strikes us least favorably. We think that not sufficient stress has been laid upon the great variations inside each race, and that too much is made of the peculiarities of the "lower" races, which in some respects might be called rather exaggerated human types than simian in character. The second chapter, " The Psychical Elements of Ethnography," is a succinct presentation of the chief causes governing the development of society. The author distinguishes associative and dispersive elements: the former including the social instinct, language, religion, and arts; the latter, the migratory and combative instincts. Dr. Brinton is inclined to consider the sexual instincts and the resulting parental and filial affections to be the prime cause of association, and rejects all theories based on promiscuity. The third chapter will be found full of interest, more particularly where the author sets forth his ideas regarding the development of man, as well as his classification of mankind. Although he knows how to present his views with much force, we cannot consider his description of the earliest stages more than an ingenious hy pothesis, because we have so far no means of reconstructing the history of the period immediately after man had made his appearance. Dr. Brinton believes that mankind during the preglacial period was homogeneous, his industries paleolithic with simple implements, his migrations extensive, his language rudimentary. Such speculations can neitber be proved nor disproved. Even the character of the glacial period, as described by Dr. Brinton, is largely hypothetical. He believes the migrations to have been limited at the time, the races to be living in fixed areas. It seems impossible to fix any period for these events which have certainly taken place at some time. The author's general ethnographic classification is based on physical characters. According to these, he distinguishes Eurafrican, Austafrican, Asian, American, and 